\title{
Incentive Memory: Evidence the Basolateral Amygdala Encodes and the Insular Cortex Retrieves Outcome Values to Guide Choice between Goal-Directed Actions
}

\author{
Shauna L. Parkes and Bernard W. Balleine \\ Brain and Mind Research Institute, University of Sydney, Camperdown, New South Wales 2050, Australia
}

Choice between goal-directed actions is determined by the relative value of their consequences. Such values are encoded during incentive learning and later retrieved to guide performance. Although the basolateral amygdala (BLA) and the gustatory region of insular cortex (IC) have been implicated in these processes, their relative contribution is still a matter of debate. Here we assessed whether these structures interact during incentive learning and retrieval to guide choice. In these experiments, rats were trained on two actions for distinct outcomes after which one of the two outcomes was devalued by specific satiety immediately before a choice extinction test. We first confirmed that, relative to appropriate controls, outcome devaluation recruited both the BLA and IC based on activation of the immediate early gene Arc; however, we found that infusion of the NMDAr antagonist ifenprodil into the BLA only abolished outcome devaluation when given before devaluation. In contrast, ifenprodil infusion into the IC was effective whether made before devaluation or test. We hypothesized that the BLA encodes and the IC retrieves incentive value for choice and, to test this, developed a novel sequential disconnection procedure. Blocking NMDAr activation unilaterally in the BLA before devaluation and then contralaterally in the IC before test abolished selective devaluation. In contrast, reversing the order of these infusions left devaluation intact. These results confirm that the BLA and IC form a circuit mediating the encoding and retrieval of outcome values, with the BLA encoding and the IC retrieving such values to guide choice.

\section{Introduction}

Choice between goal-directed actions depends on an animal's ability to integrate the relationship between actions and their consequences with changes in the relative reward or incentive value of those consequences (Dickinson and Balleine, 1994; Balleine, 2001, 2005). Sensory-specific satiety is extremely effective in producing such changes in incentive value by allowing animals to experience the reduced value of foods during the progressive satiety produced by their consumption and strongly alters the performance of actions that gain access to those incentives (Balleine, 1992; Balleine and Dickinson, 1998). It is well established that, when hungry rats have been trained on two actions for distinct foods, satiety on one of the two foods biases later choices in an extinction test away from the action that, in training, delivered the now devalued food outcome (Balleine and Dickinson, 1998).

The basolateral amygdala (BLA), a region heavily implicated in evaluative learning, is also involved in these effects of specific

\footnotetext{
Received Oct. 30, 2012; revised April 4, 2013; accepted April 9, 2013.

Author contributions: S.L.P. and B.W.B. designed research; S.L.P. performed research; S.L.P. analyzed data; S.L.P. and B.W.B. wrote the paper.

This work was supported by National Institute of Mental Health Grant MH56446, National Health and Medical Research Council Grant 633267, and Australian Research Council Laureate Fellowship FL0992409 to B.W.B. We thank Yiming Cao for his assistance.

The authors declare no competing financial interests.

Correspondence should be addressed to Dr. Bernard W. Balleine, Brain and Mind Research Institute, University of Sydney, 94 Mallett Street, Camperdown, NSW 2050, Australia. E-mail: bernard.balleine@sydney.edu.au.

DOI:10.1523/JNEUROSCI.5071-12.2013

Copyright $\odot 2013$ the authors $\quad 0270-6474 / 13 / 338753-11 \$ 15.00 / 0$
}

satiety, which are impaired in rats with bilateral lesions of the BLA (Balleine et al., 2003; Corbit and Balleine, 2005; Coutureau et al., 2009; Johnson et al., 2009) or following disconnection of the BLA from the nucleus accumbens core (Shiflett and Balleine, 2010). Similarly, the influence of specific satiety on object preference effects in primates, induced by pairing novel objects or stimuli with reward, are abolished by BLA inactivation (Wellman et al., 2005), and similar effects have been found in rats when inactivation was induced before devaluation but not before test (Wassum et al., 2009; West et al., 2012), suggesting that the BLA may be involved in encoding but not retrieving changes in incentive value.

Evidence has, indeed, implicated the gustatory region of the anterior insular cortex (IC) in the retrieval of incentive value during choice (Balleine and Dickinson, 2000). In contrast to lesions of the BLA, bilateral IC lesions abolished specific satiety-induced outcome devaluation but only when assessed on test, suggesting the IC is critical for recalling the incentive value of the outcome during choice. Although direct evidence for this role is lacking, the IC shares strong reciprocal connections with the BLA (Sripanidkulchai et al., 1984; Yamamoto, 2006). Moreover, stimulation of the BLA affects the response of IC neurons (Yamamoto et al., 1984; Piette et al., 2012) and tetanic stimulation of the BLA induces NMDA receptor-dependent long-term potentiation in the ipsilateral IC (Escobar et al., 1998a, 1998b; Escobar and BermúdezRattoni, 2000; Jones et al., 1999). It seems reasonable to propose, therefore, that the BLA encodes incentive values, 
whereas communication between the BLA and IC is critical for retrieving those values.

To evaluate this hypothesis, we first confirmed the recruitment of both the BLA and IC during outcome devaluation using the immediate early gene $A r c$. We then assessed their relative involvement in devaluation and choice by infusing an NMDA receptor antagonist either before the specific satiety treatment or before test. Finally, we assessed the temporal specificity of communication between the BLA and IC during encoding and retrieval of incentive value using a novel sequential disconnection procedure.

\section{Materials and Methods}

\section{Subjects}

Subjects were experimentally naive male outbred Long-Evans rats (280350 g) obtained from Monash University Animal Research Platform. They were housed in plastic boxes ( 2 or 3 rats per box) located in a climate-controlled colony room and were maintained on a $12 \mathrm{~h}$ light/ dark cycle. Five days before the behavioral procedures, the rats were handled daily and put on a food restriction schedule to maintain them at $\sim 85 \%$ of their ad libitum feeding weight. All experimental procedures were approved by the Animal Ethics Committee at the University of Sydney.

\section{Behavioral apparatus}

Training and testing took place in 16 MED Associates operant chambers enclosed in sound- and light-resistant shells. Each chamber was equipped with two pellet dispensers that delivered either a $45 \mathrm{mg}$ grain food pellet or a $45 \mathrm{mg}$ purified food pellet (Bioserv Biotechnologies) into a recessed magazine when activated. The chambers contained two retractable levers that could be inserted to the left and the right of the magazine. An infrared photobeam crossed the magazine opening, allowing for the detection of head entries. A $3 \mathrm{~W}, 24 \mathrm{~V}$ house light provided illumination of the operant chamber. A set of two microcomputers running MED Associates proprietary software (Med-PC) controlled all experimental events and recorded lever presses and magazine entries.

\section{Experiment 1: effect of specific satiety-induced outcome} devaluation on Arc immunoreactivity in the amygdala and IC In Experiment 1, hungry rats were trained to perform two instrumental actions for two distinct outcomes (see below). After training, rats were randomly allocated to one of three devaluation conditions: group Outcome $(n=8)$ received $1 \mathrm{~h}$ access to one of the two outcomes (grain or purified pellets), group Chow $(n=8)$ received $1 \mathrm{~h}$ access to their homecage chow, and group No food $(n=7)$ were given a $1 \mathrm{~h}$ exposure to the feeding chambers without food. Rats were killed immediately after this treatment for immunohistochemistry with the immediate early gene Arc. Another group of rats were allocated to the same devaluation conditions: group Outcome $(n=14)$, group Chow $(n=12)$, and group No food $(n=13)$ and immediately after devaluation they received an instrumental choice extinction test.

Behavioral testing procedures: instrumental training. After $5 \mathrm{~d}$ of food restriction, rats were given two sessions of magazine training to familiarize them with entering the magazine for the outcomes. Rats were confined to the operant chamber while $45 \mathrm{mg}$ grain and purified pellets were delivered at random $60 \mathrm{~s}$ intervals. Forty outcomes were delivered per session, 20 grain and 20 purified pellets. Rats then received $9 \mathrm{~d}$ of instrumental training during which two responses (left and right lever presses) were trained with the two different outcomes (grain and purified pellets) in the same session. During the session, each lever was presented twice for a maximum of $10 \mathrm{~min}$ each or until 20 outcomes were earned (i.e., rats could earn a maximum of 40 grain and 40 purified pellets within the session). The intertrial interval between lever presentations was $2.5 \mathrm{~min}$. The order of the lever presentation was alternated and was counterbalanced across rats and days. Response-outcome relationships were also counterbalanced across rats. For the first 3 d, lever pressing was continuously reinforced. Then, the probability of the outcome given a response was gradually shifted over days using increasing random ratio (RR) schedules: a RR5 schedule (probability of receiving an outcome given a response $=0.2$ ) was used on days $4-6$ and a RR10 (probability of receiving an outcome given a response $=0.1$ ) schedule was used on days 7-9.

Outcome devaluation test. After training, rats were randomly allocated to one of three devaluation conditions: group Outcome $(n=8)$ received $1 \mathrm{~h}$ access to one of the two outcomes (grain or purified pellets; $20 \mathrm{~g}$ ), group Chow $(n=8)$ received $1 \mathrm{~h}$ access to their home-cage chow $(20 \mathrm{~g})$, and group No food $(n=7)$ were given a $1 \mathrm{~h}$ exposure to separate feeding chambers (clear plastic tubs located in a different room to that used for training) without food. Rats were killed immediately after this treatment for immunohistochemistry with the immediate early gene Arc. Another group of rats were allocated to the same devaluation conditions: group Outcome $(n=14)$, group Chow $(n=12)$, and group No food $(n=13)$ and immediately after devaluation they received a 5 min instrumental choice extinction test, in which both levers were available but no outcome was delivered. Testing in extinction ensured that the rats had to recall both the current action-outcome contingencies and the current values of the two instrumental outcomes.

Immunohistochemistry. One hour after the start of the devaluation treatment, rats were rapidly and deeply anesthetized with sodium pentobarbital and perfused through the heart with ice-cold $4 \%$ paraformaldehyde in $0.1 \mathrm{~m}$ phosphate buffer. Brains were removed and postfixed in $4 \%$ paraformaldehyde overnight. Subsequently, $30 \mu \mathrm{m}$ free-floating coronal sections were cut using a vibratome (Leica). Every fourth section was collected to form a series and processed for Arc-immunoreactivity (ArcIR). Free-floating sections were prepared by rinsing in alcohol (50\%), alcohol $(50 \%)$ containing hydrogen peroxide $(3 \%)$, and normal horse serum (5\%) in $0.1 \mathrm{~m}$ phosphate buffer ( $\mathrm{pH} 7.4)$ for 30 min each. Sections were then incubated in rabbit anti-Arc (1:15000, Synaptic Systems, $48 \mathrm{~h}$ ), followed by incubation in biotinylated donkey antirabbit (1:1000; Jackson ImmunoResearch Laboratories, $24 \mathrm{~h}$ ), both in $2 \%$ normal horse serum and $0.2 \%$ Triton $\mathrm{X}$ in phosphate buffer $\left(\right.$ at $4^{\circ} \mathrm{C}$, with gentle agitation). Next, sections were incubated for $2 \mathrm{~h}$ at room temperature in VectaStain ABC Elite reagent $(6 \mu \mathrm{l} / \mathrm{ml}$ avidin and $6 \mu \mathrm{l} / \mathrm{ml}$ biotin; Vector Laboratories). A nickel intensified 3,3-diaminobenzidine (DAB) solution was used to reveal black IR. After $10 \mathrm{~min}$, glucose oxidase $(0.2 \mu \mathrm{l} / \mathrm{ml}$ DAB solution, Sigma-Aldrich) was added to the DAB solution, which contained $0.05 \% \mathrm{DAB}, 0.2 \% \mathrm{D}$-glucose; $0.04 \%$ ammonium chloride, and $1 \%$ nickel sulfate in a $0.1 \mathrm{~m}$ acetate buffer $(\mathrm{pH} 6)$. The reaction was stopped after 9 min using acetate buffer and sections were washed in phosphate buffer. Finally, sections were mounted onto gelatin-coated slides, cleared with histolene, and coverslipped with Entellan (Biolab).

Cell counts. Arc-IR was manually counted by an observer unaware of group allocations, using a transmitted light microscope at $10 \times$ magnification. Counts were made across consecutive sections of the collected series on one side of the brain. In each rat, the number of Arc-IR cells was quantified within predefined boundaries delineating each neural structure according to Paxinos and Watson (1998), unless otherwise stated. When landmarks did not clearly delineate regions, boundaries were created with a $10 \times 10$ grid reticule $(1 \mathrm{~mm} \times 1 \mathrm{~mm})$ located in the right eye piece of the microscope. Ten graduations of the grid were equivalent to $0.1 \mathrm{~mm}$ of the section. The amygdala was assessed over four sections beginning at bregma -2.56 . The lateral part of the amygdala was restricted to the triangular shaped region of the external capsule. The lateral amygdala was separated from the BLA by drawing a horizontal line through the center of the central nucleus of the amygdala. The IC was assessed over eight sections between bregma $1.7 \mathrm{~mm}$ and $0.48 \mathrm{~mm}$. Anatomical tracing studies have demonstrated that this anterior region of the IC is reciprocally connected to the basolateral amygdala (Krettek and Price, 1977; Sripanidkulchai et al., 1984; McDonald, 1998; Shi and Cassell, 1998; Pitkanen, 2000; Price, 2003). In addition, lesion (Balleine and Dickinson, 2000), imaging (Accolla et al., 2007), and electrophysiological studies (Piette et al., 2012) have demonstrated that the anterior portion of the insular ( $\sim 0.7$ to $+1.7 \mathrm{~mm}$ from bregma) is important for encoding taste-related information. The grid was placed above the piriform cortex and was used to count a $2 \mathrm{~mm}$ (height) $\times 1 \mathrm{~mm}$ (width) region containing the agranular IC, dorsal part (AID), agranular IC, ventral part (AIV), dysgranular IC, and granular IC. 
Experiments 2-4: effect of ifenprodil infused into the BLA and IC on encoding and retrieval of changes in outcome value

Surgery and drug infusions. Before behavioral testing, rats $(n=68)$ were implanted with bilateral guide cannula directed toward the basolateral amygdala (Experiment 2) and the anterior portion of the IC (Experiment 3). The BLA and the IC have strong reciprocal connections that are primarily ipsilateral (Krettek and Price, 1977; Sripanidkulchai et al., 1984; McDonald, 1998; Shi and Cassell, 1998; Pitkanen, 2000; Price, 2003). Therefore, in Experiment 4, we used a sequential disconnection procedure that prevents direct communication between the two structures (see Fig. 6A). Rats were implanted with a unilateral cannula aimed at the BLA and a unilateral cannula aimed at the contralateral IC. The hemisphere of each cannula was counterbalanced across rats. That is, for half of the rats, the cannula aimed at the BLA was located in the right hemisphere and the cannula aimed at the IC was located in the left hemisphere, whereas for the remaining rats, the cannula aimed at the BLA was located in the left hemisphere and the cannula aimed at the IC was located in the right hemisphere. Rats were anesthetized using isoflurane (Laser Animal Health) mixed with oxygen and were subcutaneously injected with $0.1 \mathrm{ml}$ solution of rimadyl and $0.1 \mathrm{ml}$ solution of bupivacaine. Anesthetized rats were mounted on a stereotaxic apparatus (David Kopf Instruments), and 26 gauge guide cannula (Plastics One) were implanted through holes drilled in both hemispheres of the skull. In Experiment 2, the tips of the guide cannula were aimed bilaterally at the BLA using the following coordinates: anteroposterior, $-2.5 \mathrm{~mm}$; mediolateral, $\pm 4.7 \mathrm{~mm}$; dorsoventral, $-7.8 \mathrm{~mm}$ (from skull surface). In Experiment 3 , the tips of the guide cannula were aimed bilaterally at the IC using the following coordinates: anteroposterior, $0.8 \mathrm{~mm}$; mediolateral, \pm 4.0 $\mathrm{mm}$; dorsoventral, $-6.5 \mathrm{~mm}$ (from skull surface) at an angle of $6^{\circ}$. In Experiment 4, one guide cannula was aimed at the BLA and one guide cannula was aimed at the contralateral IC using the above coordinates. All coordinates given are distance from bregma according to the rat brain atlas of Paxinos and Watson (1998). The guide cannulae were maintained in position with dental cement and dummy cannulae were kept in each guide at all times, except during microinfusions. Immediately after the surgical procedure, rats were injected intraperitoneally with a prophylactic $(0.3 \mathrm{ml})$ dose of $300 \mathrm{mg} / \mathrm{kg}$ solution of procaine penicillin. Rats were allowed $4 \mathrm{~d}$ to recover from surgery, during which time they were handled and weighed daily.

Infusions. Ifenprodil or vehicle was infused bilaterally in the BLA or IC by inserting a 33 gauge internal cannula into the guide cannula. The internal cannula was connected a $25 \mu$ l glass syringe attached to an infusion pump (Harvard Apparatus) and projected an additional $1 \mathrm{~mm}$ ventral to the tip of the guide cannula. A total volume of $0.3 \mu \mathrm{l}$ was delivered to both sides at a rate of $0.1 \mu \mathrm{l} / \mathrm{min}$ for infusions into the BLA. A total volume of $0.5 \mu \mathrm{l}$ was delivered to both sides at a rate of $0.25 \mu \mathrm{l} / \mathrm{min}$ for infusions into the IC. The internal cannula remained in place for a further $1 \mathrm{~min}$ after the infusions and was then removed. One day before infusions, the dummy cannulae were removed, and the infusion pump turned on for 3-5 min to familiarize the rats with the procedure and thereby minimize stress.

Drugs. Ifenprodil tartrate salt, an NMDAr antagonist with selective targeting of receptors that contain the NR2B subunit (Sigma-Aldrich), was dissolved in a solution of $0.9 \%$ nonpyrogenic saline $(\mathrm{w} / \mathrm{v})$ containing $5 \%$ of (2-hydrocypropryl)- $\beta$-cyclodextrin (Sigma-Aldrich). This latter solution was used as a vehicle. Ifenprodil tartrate salt was microinjected into the BLA or IC at a final concentration of $1 \mu \mathrm{g} / 0.3 \mu \mathrm{l}$. The interval between drug administration and behavior was $15 \mathrm{~min}$. This interval was selected on the basis of pilot studies in this laboratory.

Behavioral testing procedures: instrumental training. Instrumental training in Experiments 2-4 was exactly as described in Experiment 1 with two sessions of magazine training followed by $9 \mathrm{~d}$ of instrumental training during which two responses (left and right lever presses) were trained with the two different outcomes (grain and purified pellets) in the same session as described above. Again, lever pressing was continuously reinforced for $3 \mathrm{~d}$, an RR5 schedule ( $p=0.2)$ was used on days $4-6$ and an RR10 ( $p=0.1)$ schedule was used on days 7-9.

Outcome devaluation test. Two outcome devaluation tests were conducted in Experiments 2 and 3. These tests were identical to those in
Experiment 1, except that all rats were prefed with one of the outcomes and were given an infusion of ifenprodil or vehicle into the BLA (Experiment 2) or IC (Experiment 3) either $15 \mathrm{~min}$ before devaluation or 15 min before the choice extinction test. All rats were then given $1 \mathrm{~d}$ of rest and on the following day received an additional instrumental training session on the RR10 schedule. Twenty-four hours after retraining, rats were given another outcome devaluation test. Rats that had previously received a vehicle infusion now received ifenprodil, whereas rats that had previously received an ifenprodil infusion now received vehicle.

In Experiment 4, rats received one devaluation test $24 \mathrm{~h}$ after the final instrumental training session. The test was identical to that described above. Rats received access to one of the two outcomes (grain or purified pellets; $20 \mathrm{~g}$ ) for $1 \mathrm{~h}$ in distinct feeding cages. Half of the rats in each response-outcome assignment received grain pellets and the remaining rats received purified pellets. Immediately after devaluation, rats were given a 5 min choice extinction test in which both levers were available but no outcome was delivered. All rats received a unilateral infusion of ifenprodil before devaluation and before the choice test. Half of the rats were given an infusion into the BLA 15 min before devaluation and an infusion into the contralateral IC $15 \mathrm{~min}$ before the choice extinction test (group BLA $\rightarrow$ IC). The remaining rats were given an infusion into the IC $15 \mathrm{~min}$ before devaluation and an infusion into the contralateral BLA 15 min before the choice extinction test (group IC $\rightarrow$ BLA).

Consumption test of specific satiety. After the final outcome devaluation test, all of the rats in Experiments 2 and 3 received a consummatory version of the specific satiety test. Rats again received access to one of the two outcomes (grain or purified pellets; $20 \mathrm{~g}$ ) for $1 \mathrm{~h}$ in the feeding cages and were then given access to both outcomes for $10 \mathrm{~min}$ and the total amount consumed of each outcome (valued and devalued) was recorded. Rats were infused with either vehicle or ifenprodil before devaluation or before the consumption test. All rats were then given $1 \mathrm{~d}$ of rest and on the following day received another consumption test. Rats that had previously received a vehicle infusion now received ifenprodil, whereas rats that had previously received an ifenprodil infusion now received vehicle.

In Experiment 4, rats received one consummatory test. The test was identical to that described above. Rats received access to one of the two outcomes (grain or purified pellets; $20 \mathrm{~g}$ ) for $1 \mathrm{~h}$ in the feeding cages and were then given access to both outcomes for $10 \mathrm{~min}$, and the total amount consumed of each outcome was recorded. All rats received a unilateral infusion of ifenprodil before devaluation and another unilateral infusion of ifenprodil before the consumption test. Half of the rats were given an infusion into the BLA before devaluation and an infusion into the contralateral IC before the choice extinction test (group BLA $\rightarrow$ IC). The remaining rats were given an infusion into the IC before devaluation and an infusion into the contralateral BLA before the choice extinction test (group IC $\rightarrow$ BLA).

Histology. Subsequent to behavioral testing, subjects received a lethal dose of sodium pentobarbital. The brains were removed and sectioned coronally at $40 \mu \mathrm{m}$ through the BLA (Experiment 2), the IC (Experiment 3 ), and both the BLA and the IC (Experiment 4). Every third section was collected on a slide and stained with cresyl violet. The location of cannula tips was determined under a microscope by a trained observer, unaware of the subjects' group designations, using the boundaries defined by the atlas of Paxinos and Watson (1998). Subjects with inaccurate cannula placement were excluded from the statistical analysis.

\section{Data analyses}

All analyses of the instrumental training data were conducted using a mixed-model ANOVA. Test data in Experiments 2 and 3 were analyzed using a $2 \times 2$ within-subjects ANOVA followed by simple main effects analyses to establish the source of any significant interactions. Test data in Experiment 4 were analyzed using a mixed-model ANOVA followed by simple effects analyses to establish the source of any interaction. Arc-IR counts in each region were summed across sections. These data were analyzed using planned, orthogonal contrasts controlling the percontrast error rate (Hays, 1963). Significance was set at $\alpha=0.05$. 
A

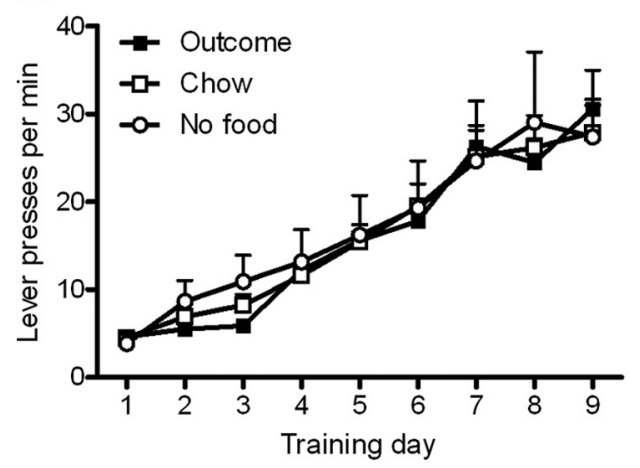

B

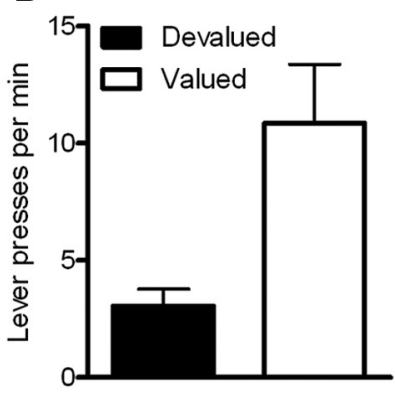

C

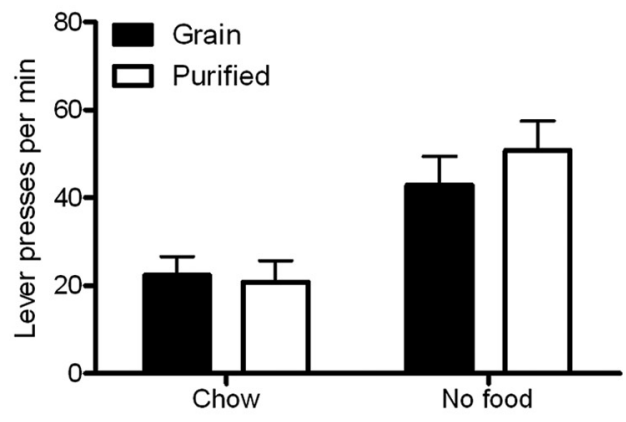

Figure 1. Experiment 1.A, Mean ( \pm SEM) lever presses per minute across sessions of instrumental training averaged across the two instrumental actions for rats allocated to group 0utcome ( $\square$ $n=14)$, group Chow $(\square ; n=12$ ) and group No food $(O ; n=13)$. Mean ( $\square$ SEM) lever presses per minute during the instrumental choice test, shown as a percentage of baseline responding during the final $2 \mathrm{~d}$ of instrumental training, for group Outcome $(\boldsymbol{B})$ and $(\boldsymbol{C})$ for groups Chow and No food. Rats in group Outcome showed increased lever pressing on the lever associated with the valued outcome (white bar) compared with the lever associated with the devalued outcome (black bar). Rats that received home-cage chow or no food during devaluation pressed equally on both levers.

\section{Results}

Experiment 1: specific satiety-induced outcome devaluation is associated with increased Arc immunoreactivity in the basolateral amygdala and the IC

Behavioral results

As shown in Figure 1A, lever press performance increased over the course of instrumental training and did not differ between groups. Statistical analyses revealed a significant effect of session $\left(F_{(1,36)}=201.84, p<0.05\right)$ but no effect of group or an interaction between these factors $\left(F_{(1,36)}<1, p>0.05\right)$. The amount of the outcome (grain or purified pellets) and chow consumed during the $1 \mathrm{~h}$ devaluation session did not differ significantly $\left(F_{(1,24)}\right.$ $<1, p>0.05)$. On average, rats consumed $9.2( \pm 0.7) \mathrm{g}$ of the outcome and $8.3( \pm 0.5)$ g of laboratory chow. The amount of grain versus purified pellets consumed did not differ $\left(F_{(1,12)}<1\right.$, $p>0.05)$. On average, rats consumed $9.4( \pm 0.7) \mathrm{g}$ of grain pellets and $9( \pm 1.2) \mathrm{g}$ of purified pellets. Performance during the outcome devaluation choice extinction test is presented in Figure $1 B$, $C$. Group Outcome showed a clear selective devaluation effect, responding markedly less on the lever that, in training, had delivered the now devalued outcome relative to the other action (Fig. $\left.1 B ; F_{(1,13)}=8.6, p<0.05\right)$. Figure $1 C$ shows the rate of lever pressing for rats in groups Chow and No food. Overall, rats that received no food during devaluation responded significantly more than the group that received chow $\left(F_{(1,23)}=13.15, p<\right.$ $0.05)$; however, in both groups, rats responded similarly on the two levers $\left(F_{(1,23)}<1, p>0.05\right)$. There was no significant interaction between group and lever $\left(F_{(1,23)}=1.22, p>0.05\right)$.

\section{Immunohistochemistry}

Figure 2A shows representative photomicrographs of Arc-IR in the amygdala for groups Outcome, Chow, and No food, and representative areas of the amygdala regions counted are shown in Figure $2 B$. Figure $2 C$ shows the mean ( \pm SEM) total Arc labeling in the amygdala. Arc-IR in the basolateral amygdala appeared greatest in rats that consumed the outcome during the devaluation session. Statistical analyses confirmed that rats in group Outcome showed significantly more Arc-IR in the BLA than rats in groups Chow and No food $\left(F_{(1,20)}=15.35, p<0.05\right)$. Arc-IR did not differ between groups Chow and No food $(F<1.6, p>0.05)$. These effects were specific to the BLA and were not observed in the lateral or central nucleus of the amygdala (all $F$ values $<1.7$, $p>0.05$ ). Figure $2 D$ shows representative photomicrographs of Arc-IR in the IC for groups Outcome, Chow, and No food, and a representative area of the region counted is shown in Figure $2 E$. Figure $2 F$ shows the mean ( \pm SEM) total Arc labeling in the IC. Arc-IR in the IC appeared greatest in rats that consumed during the devaluation session (i.e., groups Outcome and Chow). Statistical analyses confirmed that rats in group Outcome and group Chow showed significantly more Arc-IR in the IC than rats in group No food $\left(F_{(1,20)}=19.36, p<0.05\right)$. Importantly, Arc-IR was greater in rats that consumed the outcome to satiety than in rats that consumed chow to satiety $\left(F_{(1,20)}=12.41, p<0.05\right)$.

Experiment 2: blockade of NMDA receptor transmission in the basolateral amygdala disrupts specific satiety-induced outcome devaluation before devaluation, but not before the choice test

The aim of this experiment was to determine whether NMDA receptor activity in the BLA is necessary for the encoding or retrieval of instrumental incentive value. Rats were trained to press two levers for two distinct outcomes, and then one of these outcomes was devalued by specific satiety. Immediately after devaluation, rats were given a choice extinction test in which both levers were presented but no outcomes were delivered. Rats were either infused with ifenprodil before devaluation (i.e., before updating and encoding outcome value) or before the choice test (i.e., before retrieval of outcome value).

\section{Histology}

Histological verification of the cannulae placements are presented in Figure $3 E$, which shows the location of infusion cannula tips. Six rats were excluded because of incorrect placement of the guide cannula. This yielded the following group sizes: infusion before devaluation $(n=10)$ and infusion before choice test $(n=8)$.

\section{Behavioral results}

Lever pressing performance increased across instrumental training and did not differ between rats that were to be infused before devaluation and rats that were to be infused before test. Statistical analyses confirmed a significant effect of session $\left(F_{(1,16)}=62.36, p<0.05\right)$ but no effect of group or any interaction between these factors (largest $\left.F_{(1,16)}=0.48, p>0.05\right)$. Performance during the outcome devaluation choice extinction test is presented in Figure $3 \mathrm{~A}$. Inspection of the figure suggests that rats infused with vehicle before devaluation pressed the lever associated with the valued outcome more than the lever associated with the devalued 
A
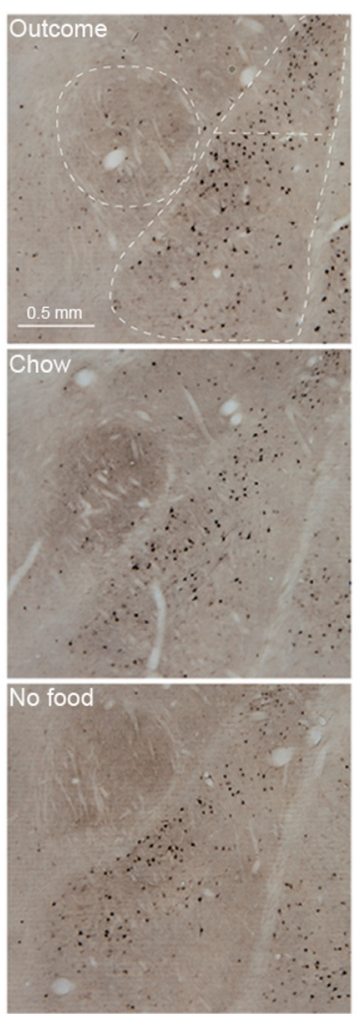

D
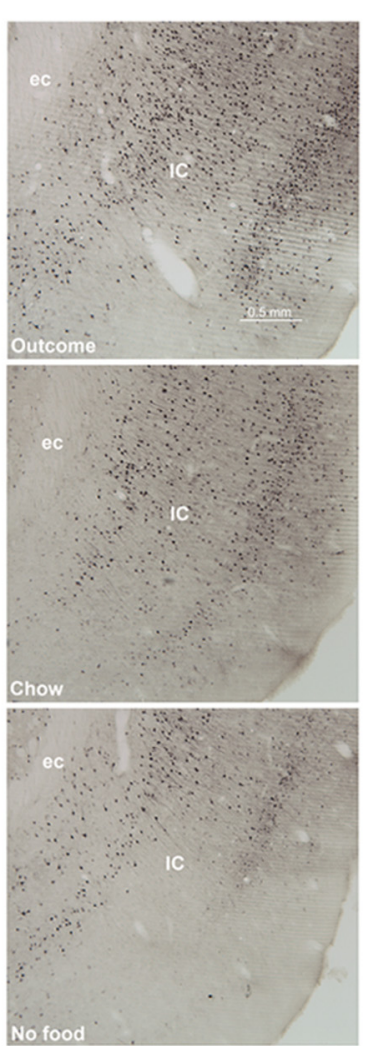

B

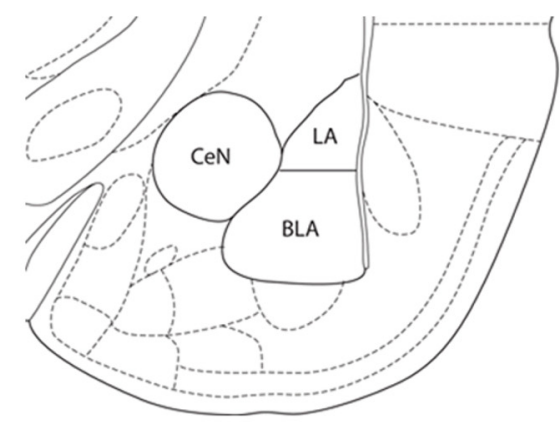

C

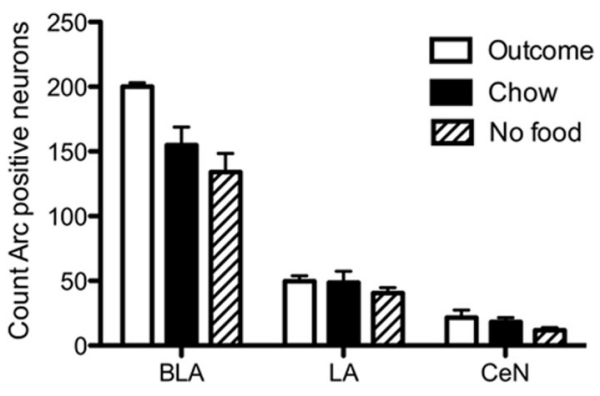

$E$

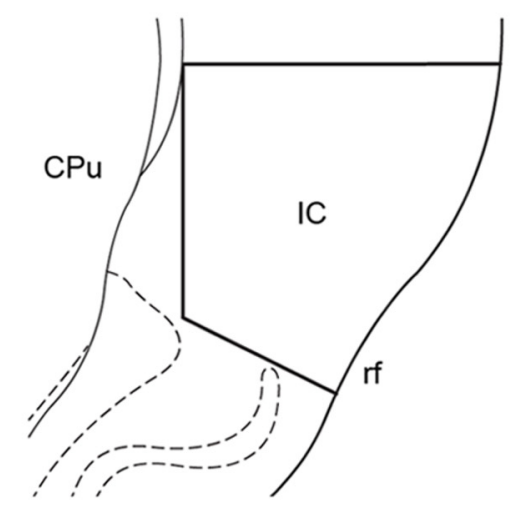

$\mathrm{F}$

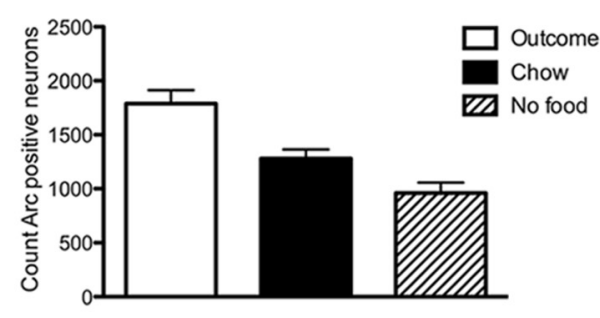

Figure 2. Experiment 1. $\boldsymbol{A}$, Representative photomicrographs of Arc-immunoreactivity (Arc-IR) in the amygdala for groups Outcome ( $(n=8)$, Chow $(n=8)$, and No food $(n=7)$. $\boldsymbol{B}$, Areas counted for Arc-IR and delineations used. CeN, Central nucleus of the amygdala; LA, lateral amygdala. C, Mean ( \pm SEM) counts of Arc-IR in the BLA, LA, and CeN for groups Outcome (white bars), Chow (black bars), and No food (striped bars). D, Representative photomicrographs of Arc-IR in the IC for groups Outcome, Chow, and No food. E, Area counted for Arc-IR and delineations used. CPU, Caudate-putamen; rf, rhinal fissure. F, Mean ( \pm SEM) counts of Arc-IR in the IC for groups Outcome (white bars), Chow (black bars), and No food (striped bars).

outcome. In contrast, rats infused with ifenprodil before devaluation pressed similarly on the valued and devalued levers. Statistical analyses confirmed these observations. A within-subjects ANOVA conducted using factors of lever (valued vs devalued) and drug (vehicle vs ifenprodil) found no effect of drug $\left(F_{(1,9)}=2.32, p>\right.$ 0.05 ), indicating the overall rate of lever pressing was similar when rats were infused with vehicle and ifenprodil. However, there was a significant effect of lever $\left(F_{(1,9)}=\right.$ 10.37, $p<0.05$ ) and a significant drug by lever interaction $\left(F_{(1,9)}=6.97, p>0.05\right)$. Simple-effects analyses conducted on the interaction found that rats pressed significantly more on the valued than the devalued lever when infused with vehicle $\left(F_{(1,9)}=11.58, p<0.05\right)$ but found no such effect when rats were infused with ifenprodil $\left(F_{(1,9)}=0.02, p>0.05\right)$. The amount of the outcome consumed under vehicle and under ifenprodil did not differ $\left(F_{(1,9)}<0.01, p>0.05\right)$. On average, rats consumed $13.4( \pm 1.2) \mathrm{g}$ under vehicle and $13.3( \pm 1) \mathrm{g}$ under ifenprodil.

Figure $3 B$ shows performance on the valued and devalued lever for rats infused before the choice extinction test. It is clear from this figure that intra-BLA infusion of ifenprodil before the choice extinction test had no effect on outcome devaluation. That is, rats infused with both vehicle and ifenprodil pressed the lever associated with the valued outcome more than the lever associated with the devalued outcome. Again, this description was confirmed by the statistical analyses. A within-subjects ANOVA using factors of lever and drug found a significant effect of lever $\left(F_{(1,7)}=5.69, p<0.05\right)$ but no significant effect of drug $\left(F_{(1,7)}=0.03, p>\right.$ $0.05)$ or any interaction between these factors $\left(F_{(1,7)}=2.56, p>0.05\right)$. The amount of the outcome consumed under vehicle and under ifenprodil did not differ $\left(F_{(1,7)}=\right.$ $0.45, p>0.05)$. On average, rats consumed $11.3( \pm 1.5) \mathrm{g}$ under vehicle and $12.0( \pm 1.1)$ $\mathrm{g}$ under ifenprodil.

\section{Consummatory devaluation test}

The results of the consumption test are shown in Figure $3 C, D$. Inspection of these figures suggests that rats infused before devaluation consumed more of the valued than the devalued food (Fig. $3 C$ ). That is, after prefeeding of one of the food outcomes, the rats ate more of a different food than the one just eaten. Importantly, the magnitude of the effect was similar under vehicle and ifenprodil infusions. Statistical analyses confirmed these observations. A within-subjects ANOVA using 

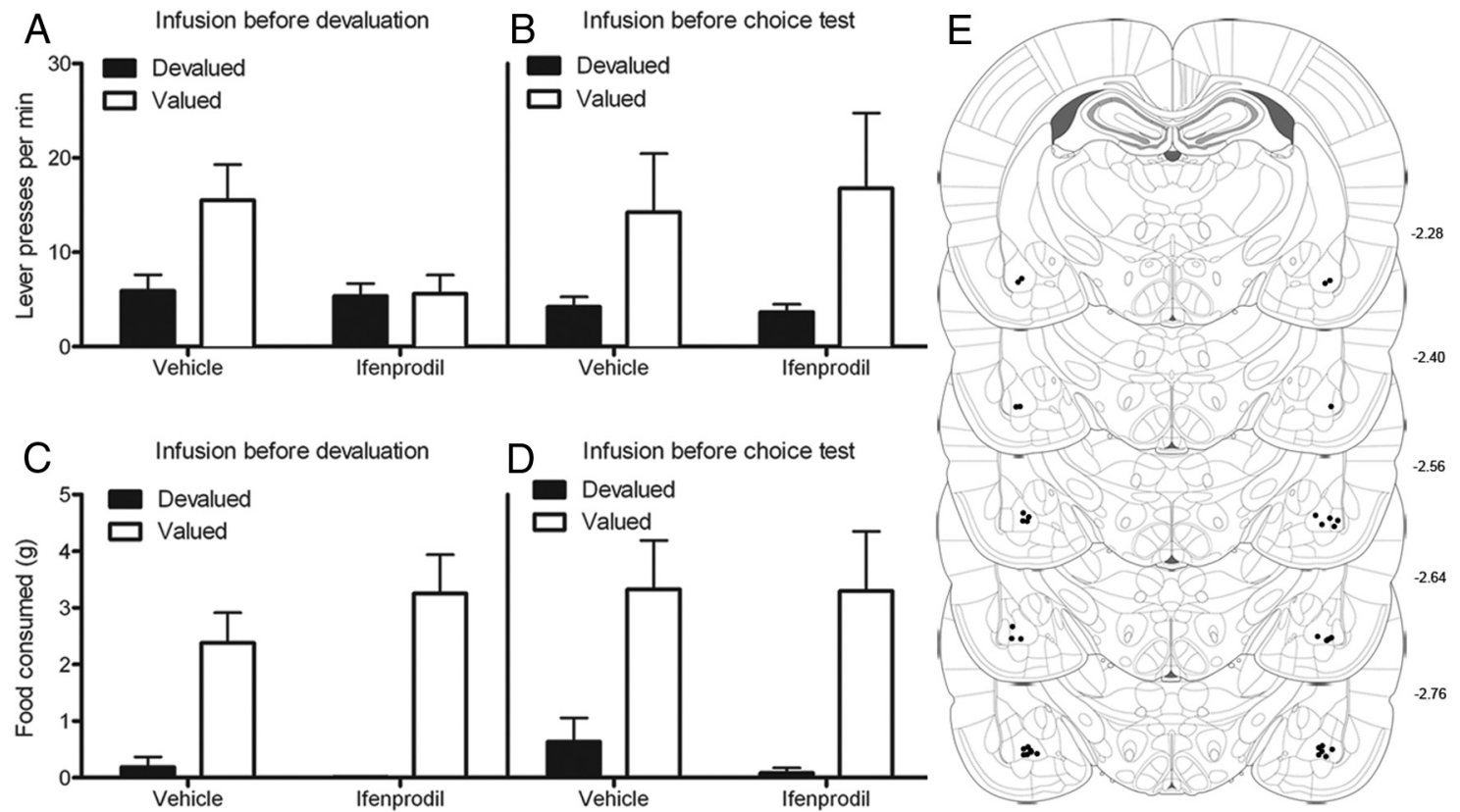

Figure 3. Experiment 2. $\boldsymbol{A}, \boldsymbol{B}$, Instrumental test of specific satiety-induced outcome devaluation. Mean ( \pm SEM) lever presses per minute in the extinction test conducted after selective devaluation of one of the outcomes for rats infused before devaluation $(n=10)(A)$ and for rats infused before the choice test $(n=8)(B)$. Responding is shown as a percentage of baseline responding during the final $2 \mathrm{~d}$ of instrumental training. White bars represent the lever associated with the valued outcome; black bars, the lever associated with the devalued outcome. $\boldsymbol{C}, \boldsymbol{D}$, Consumption test of specific satiety-induced devaluation. Mean ( \pm SEM) food consumed for rats infused before prefeeding $(\boldsymbol{C})$ and for rats infused before the test phase $(\boldsymbol{D})$. Results are presented separately for consumption of the outcome that was the same as (devalued; black bars) and different from (valued; white bars) that outcome consumed immediately before the test phase. $\boldsymbol{E}$, Microinfusion cannula placements as verified on Nissl-stained sections for the basolateral amygdala. Sections are based on Paxinos and Watson (1998).

factors of food (valued vs devalued) and drug (vehicle vs ifenprodil) revealed a significant effect of food $\left(F_{(1,9)}=56.05, p<\right.$ $0.05)$ but no significant effect of $\operatorname{drug}\left(F_{(1,9)}=0.57, p>0.05\right)$ or any interaction between these factors $\left(F_{(1,9)}=0.89, p>\right.$ $0.05)$. Similarly, rats infused before the choice consumption test ate more of the valued than the devalued food, regardless of infusion type (Fig. 3D). A within-subjects ANOVA using factors of food and drug revealed a significant effect of food $\left(F_{(1,7)}=33.77, p<0.05\right)$ but no significant effect of $\operatorname{drug}\left(F_{(1,7)}=0.17, p>0.05\right)$ or any interaction between these factors $\left(F_{(1,7)}=0.07, p>0.05\right)$.

\section{Experiment 3: blockade of NMDA receptor transmission in the IC before devaluation and before the choice test disrupts specific satiety-induced outcome devaluation}

Experiment 2 showed that activation of NMDA receptors in the BLA is necessary for the encoding, but not retrieval, of incentive value. The aim of Experiment 3 was to examine the role of the IC, a region previously implicated in outcome devaluation, in the encoding and retrieval of incentive value. Again, rats were trained to press two levers for two distinct outcomes and then one of these outcomes was devalued by specific satiety. Immediately after devaluation, rats were given a choice extinction test in which both levers were presented but no outcomes were delivered. Rats were either infused with ifenprodil before devaluation (i.e., before updating and encoding outcome value) or before the choice test (i.e., before retrieval of outcome value).

\section{Histology}

Histological verification of the cannulae placements are presented in Figure $4 E$, which shows the location of infusion cannula tips. Six rats were excluded because of incorrect placement of the guide cannula. This yielded the following group sizes: infusion before devaluation $(n=9)$ and infusion before choice test $(n=9)$.

\section{Behavioral results}

Lever pressing performance increased across instrumental training and, again, did not differ between rats that were to be infused before devaluation and rats that were to be infused before test. Statistical analyses confirmed a significant effect of session $\left(F_{(1,16)}=77.11, p<0.05\right)$ but no effect of group nor any interaction between these factors (largest $F_{(1,16)}=0.18, p>0.05$ ). Performance during the outcome devaluation choice extinction test is presented in Figure $4 A$. Inspection of the figure indicates that rats infused with vehicle before devaluation pressed the lever associated with the valued outcome more than the lever associated with the devalued outcome. In contrast, rats infused with ifenprodil before devaluation pressed equally on the valued and devalued lever. Statistical analyses confirmed these observations. A within-subjects ANOVA conducted using factors of lever (valued vs devalued) and drug (vehicle vs ifenprodil) found no effect of drug $\left(F_{(1,8)}=0.12, p>0.05\right)$, indicating that the overall rate of lever pressing was similar when rats were infused with vehicle and ifenprodil. There was no significant effect of lever $\left(F_{(1,8)}=3.13, p>0.05\right)$; however, there was a significant drug by lever interaction $\left(F_{(1,8)}=15.57, p<\right.$ $0.05)$. Simple-effects analyses conducted on the interaction found that rats pressed significantly more on the valued than the devalued lever when infused with vehicle $\left(F_{(1,8)}=6.45\right.$, $p<0.05)$ but found no such effect when rats were infused with ifenprodil $\left(F_{(1,8)}=0.21, p>0.05\right)$. The amount of the outcome consumed under vehicle and under ifenprodil did not differ $\left(F_{(1,8)}<0.01, p>0.05\right)$. On average, rats consumed 8.44 $( \pm 0.67) \mathrm{g}$ under vehicle and $8.39( \pm 0.83) \mathrm{g}$ under ifenprodil.

Figure $4 B$ shows performance on the valued and devalued lever for rats infused before the choice extinction test. Inspection of the figure suggests that rats infused with vehicle before deval- 

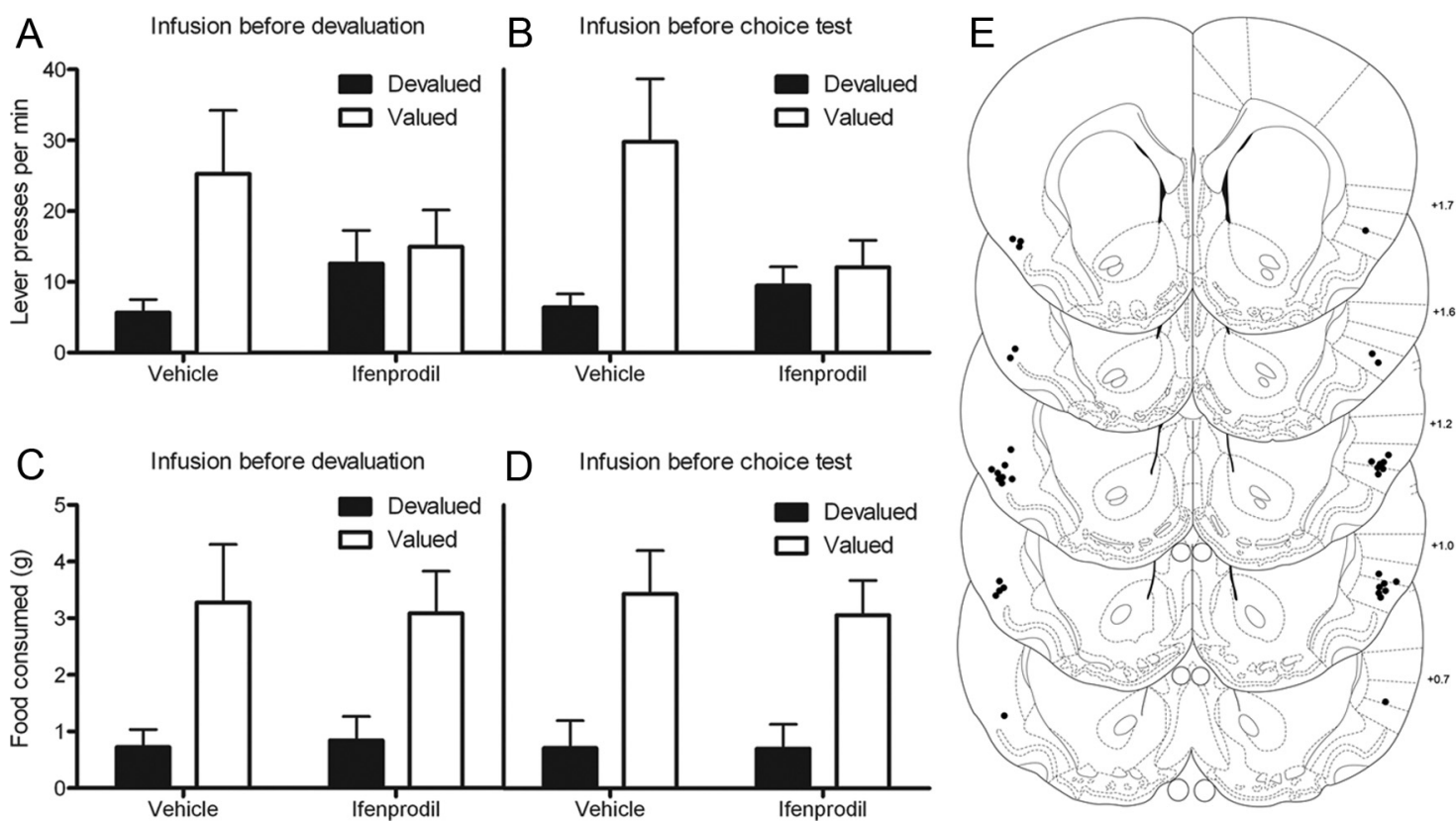

Figure 4. Experiment 3. $\boldsymbol{A}, \boldsymbol{B}$, Instrumental test of specific satiety-induced outcome devaluation. Mean ( \pm SEM) lever presses per minute in the extinction test conducted after selective devaluation of one of the outcomes for rats infused before devaluation $(n=9)(\boldsymbol{A})$ and for rats infused before the choice test $(n=9)(\boldsymbol{B})$. Responding is shown as a percentage of baseline responding during the final $2 \mathrm{~d}$ of instrumental training. White bars represent the lever associated with the valued outcome; black bars, the lever associated with the devalued outcome. C, D, Consumption test of specific satiety-induced devaluation. Mean ( \pm SEM) food consumed for rats infused before prefeeding $(\boldsymbol{C})$ and for rats infused before the test phase $(\boldsymbol{D})$. Results are presented separately for consumption of the outcome that was the same as (devalued; black bars) and different from (valued; white bars) that outcome consumed immediately before the test phase. E, Microinfusion cannula placements as verified on Nissl-stained sections for the IC. Sections are based on Paxinos and Watson (1998).

uation pressed the lever associated with the valued outcome more than the lever associated with the devalued outcome. In contrast, rats infused with ifenprodil before the choice test pressed equally on the valued and devalued lever. Statistical analyses confirmed these observations. A within-subjects ANOVA using factors of lever and drug found no effect of drug $\left(F_{(1,8)}=1.83, p>0.05\right)$. However, there was a significant effect of lever $\left(F_{(1,8)}=8.93, p<\right.$ $0.05)$ and a significant drug by lever interaction $\left(F_{(1,8)}=7.13, p<\right.$ $0.05)$. Simple-effects analyses conducted on the interaction found that rats pressed significantly more on the valued than the devalued lever when infused with vehicle $\left(F_{(1,8)}=9.38, p<0.05\right)$ but found no such effect when rats were infused with ifenprodil $\left(F_{(1,8)}=0.59, p>0.05\right)$. The amount of the outcome consumed under vehicle and under ifenprodil did not differ $\left(F_{(1,8)}=0.01\right.$, $p>0.05)$. On average, rats consumed $12.65( \pm 1.03)$ g under vehicle and $12.57( \pm 1.28) \mathrm{g}$ under ifenprodil.

Consummatory devaluation test

The results of the consumption test are shown in Figure $4 C, D$. Inspection of the figure suggests that rats infused before devaluation consumed more of the valued than the devalued food (Fig. $4 C$ ). That is, after prefeeding of one of the food outcomes, the rats ate more of a different food than the one just eaten. Importantly, the magnitude of the effect was similar under vehicle and ifenprodil infusions. Statistical analyses confirmed these observations. A within-subjects ANOVA using factors of food (valued vs devalued) and drug (vehicle vs ifenprodil) revealed a significant effect of food $\left(F_{(1,8)}=5.73, p<0.05\right)$, but no significant effect of $\operatorname{drug}\left(F_{(1,8)}<0.01, p>0.05\right)$, nor any interaction between these factors $\left(F_{(1,8)}=0.06, p>0.05\right)$. Similarly, rats infused before the choice consumption test ate more of the valued than the devalued food, regardless of infusion type (Fig. 4D). A within-subjects ANOVA using factors of food and drug revealed a significant effect of food $\left(F_{(1,8)}=6.89, p<0.05\right)$, but no significant effect of
$\operatorname{drug}\left(F_{(1,8)}=0.48, p>0.05\right)$ or any interaction between these factors $\left(F_{(1,8)}=0.39, p>0.05\right)$.

\section{Experiment 4: unilateral blockade of NMDA receptor} transmission in the basolateral amygdala before outcome devaluation, and blockade of NMDA receptor transmission in the contralateral IC before the choice test, disrupts specific satiety-induced outcome devaluation

Experiments 2 and 3 provide strong evidence that activation of NMDA receptors in the BLA is necessary for the updating and encoding, but not retrieval, of incentive value and activation of these same receptors in the IC is required for the retrieval of incentive value. Together, these results suggest that information about outcome value is encoded in the BLA and then transferred to the IC before the choice test. However, the results of Experiment 3 do not rule out the possibility that the IC is involved in both the encoding and retrieval of outcome value. The connections between the BLA and the IC are primarily ipsilateral (Krettek and Price, 1977; Sripanidkulchai et al., 1984; McDonald, 1998; Shi and Cassell, 1998; Pitkanen, 2000; Price, 2003). Stimulation of the BLA affects the response of IC neurons (Yamamoto et al., 1984; Piette et al., 2012) and induces NMDA receptor longterm potentiation in the ipsilateral IC (Escobar et al., 1998a, 1998b; Escobar and Bermúdez-Rattoni, 2000; Jones et al., 1999). Therefore, in this experiment, we developed a novel sequential disconnection procedure to more closely examine interactions between the BLA and IC in incentive learning and memory. The predictions for this experiment are presented in Figure $6 \mathrm{~A}$.

Rats were implanted with a unilateral cannula targeting the BLA and a unilateral cannula targeting the contralateral IC. If the BLA is necessary for encoding and not retrieval and the IC is necessary for retrieval but not encoding incentive value, then disrupting NMDA receptor activity in one BLA before devalua- 
tion and the contralateral IC before test should be predicted to abolish the selective devaluation effect (Group BLA $\rightarrow$ IC). This is because (with reference to Fig. $6 A$ ) encoding the change in incentive value in the BLA should be blocked in hemisphere " $h$ " but occur normally in hemisphere " $\mathrm{h}$ " " during devaluation and sent to its ipsilateral IC; however, inactivation of the IC in hemisphere $\mathrm{h}^{2}$ on test should ensure that this information will not be retrieved resulting in a deficit in outcome devaluation. In contrast, disrupting NMDA receptor activity in the IC in hemisphere $\mathrm{h}^{2}$ before devaluation and the contralateral BLA before test (Group IC $\rightarrow$ BLA) should permit devaluation to emerge because the encoded change in incentive value in the BLA of hemisphere $\mathrm{h}^{1}$ can be made available to its ipsilateral IC before retrieval on test. Experiment 2 shows that NMDA receptor transmission in the BLA is required only during devaluation and not during the choice test. Therefore, in Group IC $\rightarrow$ BLA, during devaluation, the BLA should be able to update and encode outcome value and transfer this information to the intact IC, which can then use this information to guide goal-directed performance at test.

\section{Histology}

Histological verification of the cannulae placements are presented in Figure 5, which shows the location of infusion cannula tips in the BLA (Fig. 5A) and IC (Fig. 5B). Five rats were excluded because of incorrect placement of the guide cannula. This yielded the following group sizes: BLA $\rightarrow \mathrm{IC}(n=9)$ and $\mathrm{IC} \rightarrow \operatorname{BLA}(n=10)$.

\section{Behavioral results}

Lever pressing performance increased across instrumental training and did not differ between rats assigned to Group BLA $\rightarrow$ IC and those assigned to Group IC $\rightarrow$ BLA. Statistical analyses confirmed a significant effect of session $\left(F_{(1,17)}=139.58, p<0.05\right)$, but no effect of group or any interaction between these factors (largest $\left.F_{(1,13)}=0.3, p>0.05\right)$. Performance during the outcome devaluation choice extinction test is presented in Figure $6 \mathrm{~B}$. Inspection of the figure indicates that rats infused with ifenprodil unilaterally into the BLA before devaluation and the contralateral IC before the choice test showed a deficit in outcome devaluation, pressed similarly on the valued and devalued levers. In contrast, rats infused with ifenprodil unilaterally into the IC before devaluation and the contralateral BLA before the choice test pressed the lever associated with the valued outcome more than the lever associated with the devalued outcome. Statistical analyses confirmed these observations. A mixed-model ANOVA conducted using factors of lever (valued vs devalued) and group found no effect of group $\left(F_{(1,17)}=0.01, p>\right.$ $0.05)$, indicating the overall rate of lever pressing was similar between the two groups. There was a significant effect of lever $\left(F_{(1,17)}=6.1\right.$, $p<0.05)$ and a significant group by lever interaction $\left(F_{(1,17)}=5.11\right.$, $p<0.05)$. Simple-effects analyses conducted on the interaction found that rats in group IC $\rightarrow$ BLA pressed significantly more on the valued than the devalued lever $\left(F_{(1,17)}=11.8, p<0.05\right)$ but found

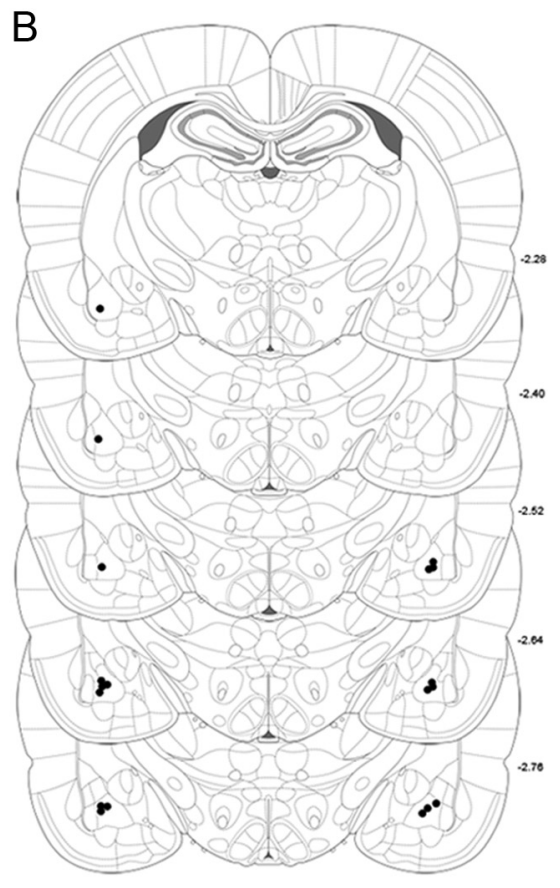

Figure 5. Experiment 4. Microinfusion cannula placements as verified on Nissl-stained sections for the insular cortex $(\boldsymbol{A})$ and basolateral amygdala (B). Sections are based on Paxinos and Watson (1998).

no such effect for rats in group BLA $\rightarrow \mathrm{IC}\left(F_{(1,17)}=0.02, p>0.05\right)$. The amount of the outcome consumed during devaluation did not differ between the two groups $\left(F_{(1,17)}=0.03, p>0.05\right)$.

\section{Consummatory devaluation test}

The results of the consumption test are shown in Figure 6C. Inspection of the figure suggests that rats in both groups consumed more of the valued than the devalued food. That is, after prefeeding of one of the food outcomes, the rats ate more of a different food than the one just eaten. Importantly, the magnitude of the effect was similar in both groups. Statistical analyses confirmed these observations. A mixed-model ANOVA using factors of food (valued versus devalued) and group revealed a significant effect of food $\left(F_{(1,17)}=19.70, p<0.05\right)$, but no significant effect of group $\left(F_{(1,17)}=0.3, p>0.05\right)$ or any interaction between these factors $\left(F_{(1,17)}=0.16, p>0.05\right)$.

\section{Discussion}

The results of the current study provide essential new information on the involvement of the BLA and IC in the encoding and retrieval of outcome values in situations in which animals have to choose between competing goal-directed actions. First, neuronal activity $(A r c)$ in the BLA and IC was increased above baseline levels immediately after a change in the incentive value of the instrumental outcome induced by specific satiety and was not affected by satiety on their maintenance diet. Second, NMDA receptor transmission in the BLA was required for encoding this change in outcome value but not for retrieving this change during a choice test. Rats infused with vehicle before devaluation or before test showed a selective devaluation effect, pressing the lever associated with the valued outcome more than the lever associated with the devalued outcome. However, whereas rats infused with ifenprodil into the BLA before the instrumental choice test showed normal devaluation, rats infused with ifenprodil before devaluation failed to show a selective devaluation effect and pressed similarly on the devalued and valued levers. 
A Infusion order: BLA $\rightarrow I C$

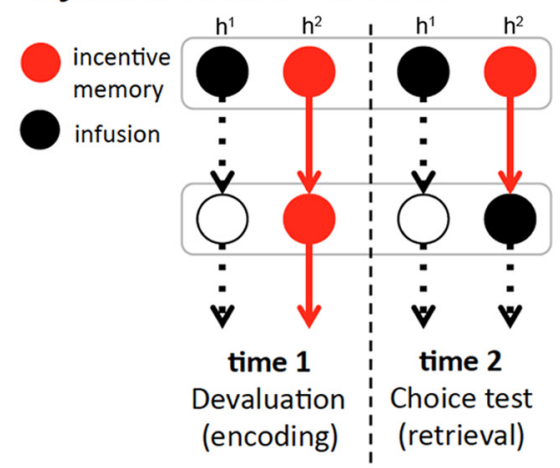

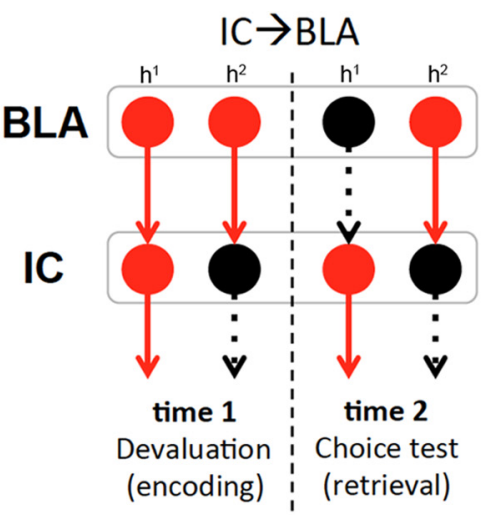

C

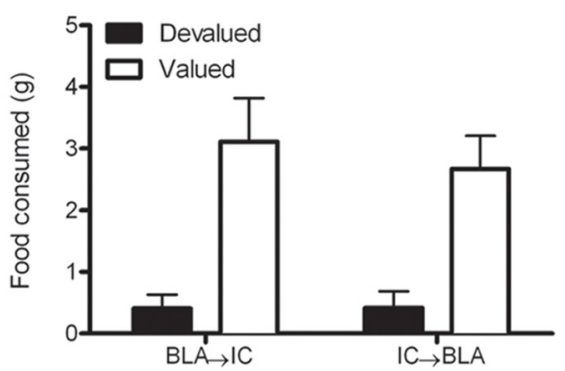

B

Instrumental test

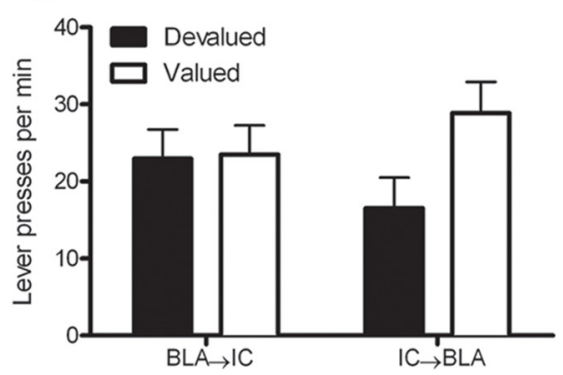

Figure 6. Experiment 4. A, Diagram of the sequential disconnection procedure used in Experiment 4 for group BLA $\rightarrow \mathrm{IC}(n=$ 9) and group IC $\rightarrow \mathrm{BLA}(n=10)$ and the predictions for this experiment. $\mathrm{h}^{1}$ and $\mathrm{h}^{2}$ indicate the ipsilateral pathways between the BLA and IC in each hemisphere. $\boldsymbol{B}$, Mean ( \pm SEM) lever presses per minute in the extinction test conducted after selective devaluation of one of the outcomes. Responding is shown as a percentage of baseline responding during the final $2 \mathrm{~d}$ of instrumental training. $C$, Mean ( \pm SEM) food consumed during the consummatory test of specific satiety-induced outcome devaluation. Results are presented separately for consumption of the outcome that was the same as (devalued; black bars) and different from (valued; white bars) that outcome consumed immediately before the test phase.

This pattern of results suggests a critical role for the BLA in encoding changes in outcome value but not in retrieving that value during choice between goal-directed actions.

In contrast, blockade of NMDA receptor transmission in the IC before devaluation and before the choice test disrupted selective devaluation. Rats infused with vehicle into the IC before devaluation and before test showed a selective devaluation effect; however, rats infused with ifenprodil at both time points failed to show this effect. Relative to the effects observed after BLA inactivation, these results suggest a critical role for the IC in retrieving outcome value during the choice test. Importantly, NMDA receptor transmission in the BLA and IC was not required for animals to show the effects of specific satiety when measured in consumption. After prefeeding one of the food outcomes, rats ate more of a different food than the one they had just eaten and to a similar degree whether given an intra-BLA or intra-IC infusion of ifenprodil or not. As such, ifenprodil does not affect discrimination between the sensory features of the two outcomes or the detection of changes in (sated) state.

These results clearly suggest that the BLA and IC interact to mediate the encoding and retrieval of incentive learning to guide choice between actions. In Experiment 4, we found direct evidence to support this claim using a novel, sequential disconnection procedure. We inactivated BLA NMDA receptors in one hemisphere before devaluation, to block encoding in that hemisphere, and NMDA receptors in the contralateral IC before the choice test, to block retrieval from that hemisphere, predicting that, together, these treatments would abolish sensitivity to changes in outcome value. In accord with this prediction, this sequential inactivation treatment produced a profound deficit in the sensitivity of the rats' choice between actions to outcome devaluation. Against this, we contrasted test performance in a group given inactivation of the same receptors but in the reverse sequence (i.e., inactivation of the IC before devaluation in one hemisphere and then the contralateral BLA before the choice). We hypothesized that, if the BLA encodes and IC retrieves incentive value, then at least one hemisphere of this group should retain the necessary information to choose appropriately on test; indeed, despite the fact that, on test, this group had the same two structures inactivated as the first group, selective devaluation was intact. Again, selective devaluation was not disrupted in either condition when measured in consumption. The results of this experiment provide strong evidence to suggest, therefore, that information about outcome value is transferred from the BLA to the IC and that this information is necessary for the effects of specific satiety-induced outcome devaluation to influence choice between instrumental actions.

Together, these findings led us to propose that the BLA and IC form a critical component of the circuit mediating instrumental incentive learning and memory. Specifically, the BLA updates and encodes information about instrumental outcome value during the specific satiety treatment (Experiments 1,2 , and 4 ) and then sends information about outcome value to the IC before the choice test (Experiments 1, 3, and 4). At test, the IC retrieves this information to guide choice between actions (Experiments 3 and 4). From this perspective, the failure to observe selective devaluation when ifenprodil was infused into the IC before devaluation may have been because inactivation renders the IC unable to receive information from the BLA about the current low value of the prefed outcome. This suggestion is consistent with the increased Arc activity detected in the IC after devaluation.

These results implicate the BLA in encoding changes in outcome value rather than to detecting those changes and is consistent with the role of the amygdala in emotional memory processes necessary for animals to integrate outcome values with the cognitive processes involved in action-outcome learning to guide subsequent choice. This specificity of BLA involvement is consistent with other reports that manipulations altering BLA activity spare the detection of changes in outcome value (Ahn and Phillips, 2002) and in outcome palatability (Wassum et al., 2009) associated with changes in motivational state. Furthermore, evidence that the BLA involvement is limited to encoding outcome value suggests an involvement in the plasticity associated with this encoding. We have previously reported evidence that the BLA plays a role in the consolidation of incentive learning through which animals encode changes in outcome value and, potentially, in its reconsolidation (Wang et al., 2005) and the fact that we were able both to observe an increase in Arc expression 
after incentive learning in the BLA and to block encoding of that learning using an NMDA receptor antagonist in the current study provides some additional impetus for this suggestion. Furthermore, other studies have found direct evidence that tetanic stimulation of the BLA can elicit long-term potentiation in the ipsilateral IC (Escobar et al., 1998a, 1998b; Escobar and Bermúdez-Rattoni, 2000). Nevertheless, what is encoded as a consequence of this plasticity is not well understood.

Previous studies examining the role of the BLA in instrumental conditioning have found evidence that it mediates the ability of rats to encode the incentive properties of specific outcomes (i.e., it mediates the connection between specific sensory properties of an outcome and its motivational and affective significance) (Balleine et al., 2003; Corbit and Balleine, 2005; Wang et al., 2005; Balleine and Killcross, 2006; Ostlund and Balleine, 2008). Consistent with this view, recent evidence has pointed to processing involving the BLA and IC associated with the palatability of specific tastes as the basis for any potential serial coding involving these structures. For example, Katz and colleagues found evidence for such an effect recording in IC after BLA ablation reporting that, although later IC responses to the palatability of various tastes were abolished, the initial taste related responses in IC were unaffected (Piette et al., 2012). Furthermore, palatability-related activity appears first in the BLA, then in the IC in paired recordings (Fontanini et al., 2009). Although it is clear that the performance of palatability responses per se is neither mediated by BLA or by anterior IC (Wassum et al., 2009; Tuerke et al., 2012), the evaluative information that drives such responses could well be embedded in a palatability signal induced during consummatory contact in the specific satiety treatment (e.g., Schoenbaum et al., 1998; Saddoris et al., 2005). Indeed, based on evidence from a wide range of incentive manipulations, Balleine $(2001,2004)$ argued that an important aspect of palatability, the hedonic or emotional responses elicited by specific outcomes, might form the basis for encoding the value of instrumental outcomes more generally.

The current results provide the basis for elaborating an incentive memory system encoding the incentive value of the instrumental outcome to guide choice between goal-directed actions. Nevertheless, it remains open to question how information encoded in the IC makes contact with the broader instrumental conditioning circuit to guide performance. One likely candidate is connections between the IC and the core region of the nucleus accumbens. Although the core appears not to be involved in the acquisition of goal-directed actions, considerable evidence has implicated this region in the selection and performance of actions based on the incentive value of the instrumental outcome. Indeed, we have recently found that disconnection of the BLA from the core abolishes the animals' sensitivity to outcome devaluation (Shiflett and Balleine, 2010). Similar effects have been observed in this pathway by other researchers. For example, phasic increases in firing rate induced by lever pressing in accumbens core were blocked by BLA inactivation (Jones et al., 2010). This analysis predicts that a comparable effect might be induced by disconnection of the IC from the core; indeed, if this is truly a three-node serial circuit, then the sequential disconnection procedure developed here could be used to demonstrate dependency between retrieval and performance in the IC-core pathway in similar fashion to the relationship between the encoding and retrieval of incentive value observed between the BLA and IC in the current study.

\section{References}

Accolla R, Bathellier B, Petersen CC, Carleton A (2007) Differential spatial representation of taste modalities in the rat gustatory cortex. J Neurosci 27:1396-1404. CrossRef Medline

Ahn S, Phillips AG (2002) Modulation by central and basolateral amygdala nuclei of dopaminergic correlates of feeding to satiety in the rat nucleus accumbens and medial prefrontal cortex. J Neurosci 22:10958-10965. Medline

Balleine B (1992) Instrumental performance following a shift in primary motivation depends on incentive learning. J Exp Psychol Anim Behav Process 18:236-250. CrossRef Medline

Balleine BW (2001) Incentive processes in instrumental conditioning. In: Handbook of contemporary learning theories (Mowrer R, Klein S, eds), pp 307-366. Hillsdale, NJ: LEA.

Balleine BW (2004) Sensation, incentive learning, and the motivational control of goal-directed action. In: Neurobiology of sensation and reward (Gottfried JA, ed), chapter 13. Boca Raton, FL: CRC.

Balleine BW (2005) Neural bases of food seeking: affect, arousal and reward in corticostriatolimbic circuits. Physiol Behav 86:717-730. CrossRef Medline

Balleine BW, Dickinson A (1998) The role of incentive learning in instrumental revaluation by specific satiety. Anim Learn Behav 26:46-59. CrossRef

Balleine BW, Dickinson A (2000) The effect of lesions of the insular cortex on instrumental conditioning: evidence for a role in incentive memory. J Neurosci 20:8954-8964. Medline

Balleine BW, Killcross S (2006) Parallel incentive processing: an integrated view of amygdala function. Trends Neurosci 29:272-279. CrossRef Medline

Balleine BW, Killcross AS, Dickinson A (2003) The effect of lesions of the basolateral amygdala on instrumental conditioning. J Neurosci 23:666675. Medline

Corbit LH, Balleine BW (2005) Double dissociation of basolateral and central amygdala lesions on the general and outcome-specific forms of Pavlovian-instrumental transfer. J Neurosci 25:962-970. CrossRef Medline

Coutureau E, Marchand AR, Di Scala G (2009) Goal-directed responding is sensitive to lesions to the prelimbic cortex or basolateral nucleus of the amygdala but not to their disconnection. Behav Neurosci 123:443-448. CrossRef Medline

Dickinson A, Balleine BW (1994) Motivational control of goal-directed action. Anim Learn Behav 22:1-18. CrossRef

Escobar ML, Bermúdez-Rattoni F (2000) Long-term potentiation in the insular cortex enhances conditioned taste aversion retention. Brain Res 852:208-212. CrossRef Medline

Escobar ML, Alcocer I, Chao V (1998a) The NMDA receptor antagonist CPP impairs conditioned taste aversion and insular cortex long-term potentiation in vivo. Brain Res 812:246-251. CrossRef Medline

Escobar ML, Chao V, Bermúdez-Rattoni F (1998b) In vivo long-term potentiation in the insular cortex: NMDA receptor dependence. Brain Res 779:314-319. CrossRef Medline

Fontanini A, Grossman SE, Figueroa JA, Katz DB (2009) Distinct subtypes of basolateral amygdala taste neurons reflect palatability and reward. J Neurosci 29:2486-2495. CrossRef Medline

Hays WL (1963) Statistics for psychologists. New York: Holt, Rinehart and Winston.

Johnson AW, Gallagher M, Holland PC (2009) The basolateral amygdala is critical to the expression of Pavlovian and instrumental outcome-specific reinforce devaluation effects. J Neurosci 29:696-704. CrossRef Medline

Jones JL, Day JJ, Wheeler RA, Carelli RM (2010) The basolateral amygdala differentially regulates conditioned neural responses within the nucleus accumbens core and shell. Neuroscience 169:1186-1198. CrossRef Medline

Jones MW, French PJ, Bliss TV, Rosenblum K (1999) Molecular mechanisms of long-term potentiation in the insular cortex in vivo. J Neurosci 21: RC36. Medline

Krettek JE, Price JL (1977) Projections from the amygdaloid complex to the cerebral conrtex and the thalamus in the rat and cat. J Comp Neurol 172:687-722. CrossRef Medline

McDonald AJ (1998) Cortical pathways to the mammalian amygdala. Prog Neurobiol 55:257-332. CrossRef Medline

Ostlund SB, Balleine BW (2008) Differential involvement of the basolateral 
amygdala and mediodorsal thalamus in instrumental action selection. J Neurosci 28:4398-4405. CrossRef Medline

Paxinos G, Watson C (1998) The rat brain in stereotaxic coordinates, Ed 4. New York: Academic.

Piette CE, Baez-Santiago MA, Reid EE, Katz DB, Moran A (2012) Inactivation of basolateral amygdala specifically eliminates palatability-related information in cortical sensory responses. J Neurosci 32:9981-9991. CrossRef Medline

Pitkanen A (2000) Connectivity of the rat amygdaloid complex. In: The amygdala: a functional analysis (Aggleton JP, ed), pp 31-116. New York: Oxford UP

Price JL (2003) Comparative aspects of amygdala connectivity. Ann N Y Acad Sci 985:50-58. CrossRef Medline

Saddoris MP, Gallagher M, Schoenbaum G (2005) Rapid associative encoding in basolateral amygdala depends on connections with orbitofrontal cortex. Neuron 46:321-331. CrossRef Medline

Schoenbaum G, Chiba AA, Gallagher M (1998) Orbitofrontal cortex and basolateral amygdala encode expected outcomes during learning. Nat Neurosci 2:155-159. CrossRef Medline

Shi CJ, Cassell MD (1998) Cortical, thalamic, and amygdaloid connections of the anterior and posterior insular cortices. J Comp Neurol 399:440 - 468. CrossRef Medline

Shiflett MW, Balleine BW (2010) At the limbic-motor interface: disconnection of the basolateral amygdala from nucleus accumbens core and shell reveals dissociable components of incentive motivation. Eur J Neurosci 32:1735-1743. CrossRef Medline
Sripanidkulchai K, Sripanidkulchai B, Wyss JM (1984) The cortical projection of the basolateral amygdaloid nucleus in the rat: a retrograde fluorescent dye study. J Comp Neurol 229:419-431. CrossRef Medline

Tuerke KJ, Limebeer CL, Fletcher PJ, Parker LA (2012) Double dissociation between regulation of conditioned disgust and taste avoidance by serotonin availability at 5-HT(3) receptor in the posterior and anterior insular cortex. J Neurosci 40:13709-13717. CrossRef Medline

Wang SH, Ostlund SB, Nader K, Balleine BW (2005) Consolidation and reconsolidation of incentive learning in the amygdala. J Neurosci 25:830 835. CrossRef Medline

Wassum KM, Ostlund SB, Maidment NT, Balleine BW (2009) Distinct opioid circuits determine the palatability and the desirability of rewarding events. Proc Natl Acad Sci U S A 106:12512-12517. CrossRef Medline

Wellman LL, Gale K, Malkova L (2005) GABA $_{\mathrm{A}}$-mediated inhibition of basolateral amygdala blocks reward devaluation in macaques. J Neurosci 25:4577-4586. CrossRef Medline

West EA, Forcelli PA, Murnen AT, McCue DL, Gale K, Malkova L (2012) Transient inactivation of basolateral amygdala during selective satiation disrupts reinforcer devaluation in rats. Behav Neurosci 126:563-574. CrossRef Medline

Yamamoto T (2006) Neural substrates for the processing of cognitive and affective aspects of taste in the brain. Arch Histol Cytol 69:243-255. CrossRef Medline

Yamamoto T, Azuma S, Kawamura Y (1984) Functional relations between the cortical gustatory area and the amygdala: electrophysiological and behavioral studies in rats. Exp Brain Res 56:23-31. Medline 